\title{
BUSINESS ANALYTICS: UNA VENTAJA COMPETITIVA EN LA TOMA DE DECISIONES PARA EMPRESAS INTELIGENTES
}

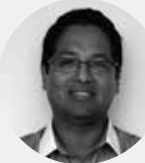

\author{
JIMMY A. ARMAS \\ - Profesor de Business Intelligence and Predictability \\ Dirección de Computación e Informática \\ Facultad de Ingeniería, UPC
}

En la actualidad, la información se vuelve cada vez más compleja, voluminosa y difícil de analizar, y la variedad de sus formatos alcanza niveles de granularidad y de detalle específico. Business analytics se define como el proceso para realizar análisis estadísticos más profundos de la información, utilizando algoritmos y datos históricos para hacer una predicción sobre el rendimiento futuro de un producto o servicio de la empresa. Este proceso contribuye eficientemente en la estrategia organizacional en la toma de decisiones, y, de ese modo, también en la automatización y optimización de los procesos de una compañía.

Las organizaciones que tengan visión de futuro para aplicar los nuevos enfoques crearán empresas inteligentes y estarán preparadas para superar a sus competidores directos e indirectos. Estas empresas inteligentes adoptan nuevas formas de trabajar, más allá de un enfoque tradicional en la toma de decisiones y en la manera en que dirigen sus operaciones. El uso de business analytics es un paso en esa dirección, con gran cantidad de tecnología e instrumentación para convertir la información en una nueva acción inteligente, pues las organizaciones necesitan de una extraordinaria capacidad de análisis, aplicada de forma extensiva y consistente. Con la información en su contexto correcto y con la perspicacia para la gestión de los negocios, los líderes podrán ahora trabajar en las cuestiones que les preocupan.

¿Cómo usar business analytics en las organizaciones? En términos generales, el empleo de business analytics consta de seis pasos: i) se identifica el problema, ii) se recogen los datos relevantes del proceso por analizar, iii) se ordenan y se limpian los datos para que sean utilizables, iv) se cargan los datos en modelos de almacenamiento de datos, v) se manipula la información que conduzca a conocimientos accionables y vi) se toman decisiones basadas en la información procesada. Este proceso debe realizarse de manera iterativa para que las empresas inteligentes conecten globalmente las funciones internas y externas por todas las zonas geográficas, departamentos, unidades de negocio y equipos, en línea

con los resultados empresariales deseados. Sin análisis de datos, las compañías no pueden mantenerse relevantes ni evolucionar, por lo que se recomienda crear una cultura empresarial que se apoye y se soporte en el análisis de datos y en herramientas de business analytics, para así generar grandes beneficios, siempre y cuando se sepa bien en qué dirección desean moverse. En especial cuando las cantidades de data se hacen más grandes y aparentemente indomables.

Las empresas inteligentes mejoran y amplían la perspectiva, el alcance y la memoria de los empleados, así como la autoridad para decidir y actuar. En la medida en que la automatización adquiera mayor protagonismo al momento de las decisiones, cada vez más rutinarias, se ha de confiar más en el juicio de los empleados para tomar decisiones de alto valor y actuar en consecuencia.

Las compañías están usando la tecnología para innovar en los negocios, generando un cambio de mente en toda la organización; es decir, un cambio cultural de alto impacto. Dos de cada tres han detectado la oportunidad y han empezado a poner en práctica el análisis para conseguir ventajas empresariales, pero únicamente una de cada ocho está en el camino correcto para conseguirlo. No obstante, visto el ritmo frenético del cambio global y de los retos organizacionales, esperamos que la adopción de las nuevas capacidades analíticas aplicadas a la optimización empresarial se dé con rapidez. 